\title{
Recurrence risk is associated with preoperatively advanced prolapse stage: Is there a difference between women with stage 2 and those with stage 3 or 4 cystocele?
}

\author{
Tineke F. M. Vergeldt ${ }^{1} \cdot \operatorname{Kim}$ J. B. Notten ${ }^{2} \cdot$ Kirsten B. Kluivers $^{1} \cdot$ Mirjam Weemhoff $^{3}$
}

Received: 26 September 2016 / Accepted: 15 November 2016 / Published online: 6 December 2016

(C) The Author(s) 2016. This article is published with open access at Springerlink.com

\begin{abstract}
Introduction and hypothesis Pelvic organ prolapse (POP) recurrence after surgery is a major problem. POP that is more advanced preoperatively is associated with a higher risk of recurrence postoperatively. We hypothesized that women with a stage 2 cystocele differ from those with a stage 3 or 4 cystocele. The aim of this study was to compare the baseline characteristics of women with mild and those with more advanced cystocele.

Methods Patients had participated in one of two multicenter prospective cohort studies on women undergoing conventional anterior colporrhaphy without previous POP surgery. This was a secondary analysis of these data. Women with a preoperative cystocele stage 2 were compared with women with a stage 3 or 4 cystocele. Logistic regression models were employed to calculate odds ratios (OR) and $95 \%$ confidence intervals (CI).

Results Two hundred and sixty-nine women were assessed, of whom $132(49.1 \%)$ had an advanced cystocele. Only older age was significantly associated with advanced cystocele preoperatively, with an OR of 1.07 (95\% CI 1.04-1.10). There were no significant differences between women with advanced or stage 2 cystocele in body mass index, vaginal deliveries, assisted delivery, positive family history of POP,
\end{abstract}

Tineke F. M. Vergeldt

Tineke.Vergeldt@ radboudumc.nl

1 Obstetrics \& Gynecology, Radboud University Medical Center, P.O.Box 9101, 6500 HB Nijmegen, The Netherlands

2 Obstetrics \& Gynecology, Maastricht University Medical Center, Maastricht, The Netherlands

3 Obstetrics \& Gynecology, Zuyderland Medical Center, Heerlen, The Netherlands concurrent rectocele, concurrent uterine of vaginal vault prolapse, major levator ani muscle defects, or levator hiatal area. Conclusions Women with advanced cystocele were significantly older than women with stage 2 cystocele. This raises the question whether it would be favorable to perform POP surgery in an earlier stage, i.e., at a younger age, in order to prevent POP recurrence.

Keywords Advanced stage $\cdot$ Age $\cdot$ Pelvic organ prolapse . Recurrence

\section{Introduction}

Female pelvic organ prolapse (POP) is a common condition that can have a great negative impact on women's social, physical, and psychological well-being [1]. Women may have symptoms such as feeling or seeing a bulge in their vagina, or they may have micturition, defecation, and sexual problems. The severity of symptoms does not correlate well with the severity of POP, and many women with POP are asymptomatic [2]. In case of symptomatic POP, options include expectant management (pelvic floor exercises, including physical therapy), pessary treatment, and surgery [3]. The lifetime risk of surgery for POP in the general female population is 13$19 \%[4,5]$. POP recurrence after surgery is a major problem, with anatomical recurrence rates reported in the literature from $31 \%$ up to $59 \%[6,7]$. Anterior-compartment prolapse, also referred to as cystocele, is the most commonly affected in POP and is the most prone for recurrence after surgery $[8,9]$.

Advanced preoperative stage seems to be an important risk factor for recurrence [7, 10-13]. In a systematic review on risk factors, it was the only risk factor associated with recurrence in at least two cohort or cross-sectional studies with multivariate analysis in a Western country [14]. This raises the 
question of whether there is a difference between women with mild and women with more advanced POP.

We hypothesized that women with a stage 2 cystocele differ from women with a stage 3 or 4 cystocele. The aim of this study was to compare baseline characteristics of women with mild to women with more advanced cystocele.

\section{Materials and methods}

Our cohort had participated in one of two multicenter prospective cohort studies concerning women undergoing conventional anterior colporrhaphy (i.e., without the use of mesh materials) performed in nine teaching hospitals in The Netherlands. This was a secondary analysis of these data. In the first study, women were assessed between January 2006 and September 2008 for a randomized controlled trial comparing indwelling catheterization for 2 versus 5 days following surgery [15]. The follow-up visits after 2 years, which included POP staging and translabial 3D ultrasound (US), were performed between November 2009 and April 2010. The aim of that study was to determine whether levator defects were a risk factor for cystocele recurrence and to identify other risk factors associated with recurrence [12]. In the second study, women were recruited from June 2010 until November 2012, with a follow-up of 1 year. The primary aim of this study was to assess the diagnostic accuracy of translabial 3D US in the diagnosis of levator defects in women with POP, using magnetic resonance imaging (MRI) as reference test $[16,17]$. The protocols of both studies were approved by the medical ethics committees of each participating hospital, and all women gave written informed consent before enrollment in the study. In both studies, women had undergone an anterior colporrhaphy without the use of mesh materials and without previous POP surgery. Anterior colporrhaphy was performed alone or in combination with other POP procedures.

All women completed a validated questionnaire, with additional questions concerning possible risk factors [18]. Pelvic examination was performed with the patient in the lithotomy position. POP staging was performed according to the Pelvic Organ Prolapse Quantification (POP-Q) scoring system in the second database [19] and according to the Baden-Walker classification in the first [20], as POP-Q classification was not generally introduced into daily practice at the time of that study. For this secondary analysis, only women with BadenWalker or POP-Q stage 2 cystocele were included. Advanced preoperative stage was defined as Baden-Walker or POP-Q stage 3 or 4 , i.e., the most distal part of the prolapse during Valsalva was bulging out of the vagina according to the Baden-Walker classification or $\geq 1 \mathrm{~cm}$ from the hymenal remnants according to the POP-Q classification. The procedure of translabial 3D US and assessment of US finding is described previously [13].
Women undergoing an anterior colporrhaphy for a stage 2 cystocele were compared with women undergoing the same procedure for a stage 3 or 4 (advanced) cystocele. Baseline characteristics investigated were age, body mass index (BMI), number of vaginal deliveries, having had an assisted vaginal delivery, positive family history of POP, concurrent rectocele, concurrent uterine or vaginal-vault prolapse, major levator ani muscle defects on US, and levator hiatal area during Valsalva on US. Positive family history of POP was defined as having (had) a mother or sister with POP. Because two databases were combined, baseline characteristics were calculated for both databases separately and combined.

We used the statistical software package SPSS version 22.0 (SPSS Inc., Chicago, IL, USA) for statistical analyses. Logistic regression models were employed to calculate odds ratios $(\mathrm{OR})$ and $95 \%$ confidence intervals $(\mathrm{CI})$. A $p$ value $<$ 0.05 was considered statistically significant.

\section{Results}

In this secondary analysis, 269 women with at least BadenWalker or POP-Q stage 2 cystocele were included: 157 (50.9\%) underwent anterior colporrhaphy for stage 2 cystocele and $132(49.1 \%)$ for stage 3 or 4 . Baseline characteristics for the two databases separately and combined are shown in Table 1. There were no significant differences except for concurrent uterine of vaginal vault prolapse, which was more frequent in the first database.

Possible risk factors for advanced cystocele with ORs and 95\% CI are shown in Table 2 . Only age was significantly associated with advanced cystocele. There were no significant differences between women with advanced or with stage 2 cystocele in BMI, number of vaginal deliveries, having undergone an assisted delivery, positive family history of POP, concurrent rectocele, concurrent uterine of vaginal vault prolapse, major levator ani muscle defects, or levator hiatal area during Valsalva. Because univariate analysis revealed only one significant risk factor, multivariate analysis was not contributory.

\section{Discussion}

In this study, characteristics of women seeking surgical treatment for stage 3 or 4 cystocele where compared with those with stage 2 cystocele. Women with advanced cystocele were significantly older.

The knowledge that more advanced POP has a higher risk of recurrence after surgery raises the question as to whether it would be favorable to perform POP surgery at an earlier stage, i.e., at a younger age, rather than to wait until POP has progressed to a more advanced stage. Although older age is a risk factor for primary POP in multiple studies [21-24], 
Table 1 Patient baseline characteristics

\begin{tabular}{|c|c|c|c|c|c|c|c|}
\hline & \multicolumn{2}{|c|}{ Total $(n=269)$} & \multicolumn{2}{|c|}{ Weemhoff $[12,15](n=130)$} & \multicolumn{2}{|c|}{ Notten $[16,17](n=139)$} & \multirow{2}{*}{$\begin{array}{l}P \\
\text { value }\end{array}$} \\
\hline & $n$ & $n$ or mean ( $\%$ or range) & $n$ & $n$ or mean ( $\%$ or range) & $n$ & $n$ or mean $(\%$ or range $)$ & \\
\hline Preoperative stage 3 or 4 (n) & 269 & $132(49.1 \%)$ & 130 & $70(53.8 \%)$ & 139 & $62(44.6 \%)$ & 0.13 \\
\hline Age (years) & 269 & $58.1(31-87)$ & 130 & $59.0(39-87)$ & 139 & $57.4(31-78)$ & 0.20 \\
\hline BMI $\left(\mathrm{kg} / \mathrm{m}^{2}\right)$ & 241 & $26.0(17.5-41.9)$ & 125 & $26.2(18.4-36.4)$ & 116 & $25.7(17.5-41.9)$ & 0.26 \\
\hline Vaginal delivery (mean) & 258 & $2.3(0-9)$ & 130 & $2.3(0-9)$ & 128 & $2.3(1-7)$ & 0.65 \\
\hline Assisted delivery (n) & 258 & $31(12.0 \%)$ & 130 & $18(13.8 \%)$ & 128 & $13(10.2 \%)$ & 0.36 \\
\hline Family history of POP (n) & 252 & $109(43.3 \%)$ & 130 & $53(40.8 \%$ & 122 & $56(45.9 \%)$ & 0.41 \\
\hline Concurrent rectocele (n) & 269 & $115(42.8 \%)$ & 130 & $58(44.6 \%)$ & 139 & $57(41.0 \%)$ & 0.55 \\
\hline Concurrent uterine or vaginal vault prolapse (n) & 269 & $161(59.9 \%)$ & 130 & $88(67.7 \%)$ & 139 & $73(52.5 \%)$ & 0.01 \\
\hline Major levator defect (n) & 262 & $119(45.4 \%)$ & 127 & $52(40.9 \%)$ & 135 & $67(49.6 \%)$ & 0.16 \\
\hline Hiatus during Valsalva $\left(\mathrm{cm}^{2}\right)$ & 256 & $33.3(16.8-67.4)$ & 122 & $32.4(18.4-56.4)$ & 134 & $34.0(16.8-67.4)$ & 0.10 \\
\hline
\end{tabular}

$B M I$ body mass index, $P O P$ pelvic organ prolapse

other studies have challenged the assumption that POP worsens over time [25-27]. Two cohort studies that investigated the likelihood of POP progression showed high grades of spontaneous regression $[25,26]$. Both studies suggested that there was little true change in POP severity over time. A retrospective cohort study to determine the association between patient age and POP has shown a weak and complex relationship [27]. There was a positive correlation between cystocele and age in premenopausal women, but this relationship was reversed after menopause. The authors concluded that ageing appeared to play only a limited role in POP etiology and pathogenesis, contradicting epidemiological studies showing age to be a risk factor for POP surgery [28]. This discrepancy may be due to confounders such as symptoms of bladder or bowel dysfunction that may become more likely with increasing urogenital atrophy, which increases with age. Therefore, surgery might generally be performed at an older age, not because POP has progressed to an advanced stage, but because of more severe symptoms at that age and the assumption that urogenital symptoms are the result of POP when in fact atrophy or overactive bladder syndrome may be the case.

Studies investigating the association between age and POP recurrence show conflicting results, as well [14]. In two studies with a cutoff at 60 years, younger age was a significant risk factor for POP recurrence after surgery $[7,10]$. In contrast, in two other studies in which age was a continuous variable and in one study with a cutoff at 70 years, no significant associations were found $[11,12,29]$. The association between age and POP recurrence is thus more complex, with both younger and older age as risk factors for POP recurrence.

Younger women with POP are often advised to postpone POP surgery until progression of complaints because of the high recurrence risk of POP and the risk that multiple surgeries will be needed over time; younger women have a longer life expectancy and therefore more time to develop recurrence. Results of the study reported here argue whether the advice to

Table 2 Logistic regression analysis

\begin{tabular}{|c|c|c|c|c|c|c|}
\hline & \multicolumn{2}{|c|}{ Stage 2 cystocele } & \multicolumn{2}{|c|}{ Stage 3 or 4 cystocele } & \multirow[t]{2}{*}{ OR $(95 \% \mathrm{CI})$} & \multirow{2}{*}{$\begin{array}{l}P \\
\text {-value }\end{array}$} \\
\hline & $n$ & $n$ or Mean ( $\%$ or range) & $n$ & $n$ or Mean ( $\%$ or range) & & \\
\hline Age (years) & 137 & $55.1(31-83)$ & 132 & $61.3(39-87)$ & $1.07(1.04-1.10)$ & $<0.01$ \\
\hline BMI $\left(\mathrm{kg} / \mathrm{m}^{2}\right)$ & 119 & $26.0(18.4-41.9)$ & 122 & $26.0(17.5-35.2)$ & $1.00(0.93-1.07)$ & 1.00 \\
\hline Vaginal delivery (n) & 129 & $2.3(0-4)$ & 129 & $2.3(0-9)$ & $1.05(0.83-1.34)$ & 0.67 \\
\hline Assisted delivery (yes/no), $n(\%)$ & 129 & $15(11.6 \%)$ & 129 & $16(12.4 \%)$ & $1.08(0.51-2.28)$ & 0.85 \\
\hline Family history of POP (yes/no), $n(\%)$ & 128 & $51(39.8 \%)$ & 124 & $58(46.8 \%)$ & $1.33(0.81-2.19)$ & 0.27 \\
\hline Concurrent rectocele (yes/no), $n(\%)$ & 136 & $63(46.3 \%)$ & 132 & $52(39.4 \%)$ & $0.76(0.47-1.24)$ & 0.28 \\
\hline Concurrent uterine of vaginal vault prolapse (yes/no), $n(\%)$ & 137 & $79(57.7 \%)$ & 132 & $82(62.1 \%)$ & $1.20(0.74-1.96)$ & 0.46 \\
\hline Major levator defect (yes/no), $n(\%)$ & 133 & $58(43.6 \%)$ & 129 & $61(47.3 \%)$ & $1.16(0.71-1.89)$ & 0.55 \\
\hline Hiatus during Valsalva $\left(\mathrm{cm}^{2}\right)$, mean (range) & 130 & $33.0(16.8-58.5)$ & 126 & $33.5(18.9-67.4)$ & $1.01(0.98-1.04)$ & 0.59 \\
\hline
\end{tabular}

$O R$ odds ratio, $C I$ confidence interval, $B M I$ body mass index, $P O P$ pelvic organ prolapse 
wait is justified. Theoretically, waiting for progression of complaints could lead to progression of POP due to stretching of tissue and ligaments. On the other hand, stiffening of vaginal tissues after menopause could lead to reduction of distensibility and reduced POP severity. Not every woman with a stage 2 cystocele will develop a stage 3 or 4 cystocele; therefore, performing surgery in every woman with stage 2 cystocele would lead to overtreatment. Possibly, pessary use may reduce the risk of progression to a stage 3 or 4 cystocele due to less tissue and ligament stretching compared with expectant management. In a prospective cohort study, no women experienced POP stage worsening with pessary use [30]. However, the study had a low sample size and short follow-up of 1 year. Among the possible risk factors investigated in the study presented here, only age was significantly associated with advanced cystocele. In future research, it may be interesting to investigate other factors that may be associated with advanced POP, such as biomechanical properties of vaginal tissue or genetic factors.

Strengths of this study are sample size and multicenter design of the studies combined in one database. There were no significant differences between the two databases, except for concurrent uterine or vaginal vault prolapse, which was more frequent in the first database. It is unlikely that this would have influenced our study results, because recurrence rates were comparable between databases. A weakness of the study is the use of two different classification systems for POP staging. Since studies that use either classification system show that advanced POP preoperatively is a risk factor for POP recurrence after surgery, the use of the different systems did not influence our study [7, 10-13]. Because our study population was mainly Caucasian, these findings cannot be extrapolated to other ethnicities.

In conclusion, women with advanced POP have a higher risk of recurrence after POP surgery. Women with advanced cystocele are significantly older than women with stage 2 cystocele. Further research is needed to determine whether it would be favorable to perform POP surgery at an earlier stage (i.e., at a younger age) in order to prevent POP recurrence.

\section{Compliance with ethical standards}

\section{Disclosure of funding ZonMW projectnumber 171001012}

\section{Conflicts of interest None.}

Open Access This article is distributed under the terms of the Creative Commons Attribution 4.0 International License (http:// creativecommons.org/licenses/by/4.0/), which permits unrestricted use, distribution, and reproduction in any medium, provided you give appropriate credit to the original author(s) and the source, provide a link to the Creative Commons license, and indicate if changes were made.

\section{References}

1. Abdel-Fattah M, Familusi A, Fielding S, Ford J, Bhattacharya S. Primary and repeat surgical treatment for female pelvic organ prolapse and incontinence in parous women in the UK: a register linkage study. BMJ Open. 2011;1(2):e000206. doi:10.1136/bmjopen-2011-000206.

2. Ghetti C, Gregory WT, Edwards SR, Otto LN, Clark AL. Pelvic organ descent and symptoms of pelvic floor disorders. Am J Obstet Gynecol. 2005;193(1):53-7. doi:10.1016/j.ajog.2004.12.004.

3. Jelovsek JE, Maher C, Barber MD. Pelvic organ prolapse. Lancet. 2007;369(9566):1027-38. doi:10.1016/s0140-6736(07)60462-0.

4. Wu JM, Matthews CA, Conover MM, Pate V, Jonsson Funk M. Lifetime risk of stress urinary incontinence or pelvic organ prolapse surgery. Obstet Gynecol. 2014;123(6):1201-6. doi:10.1097/aog.0000000000000286.

5. Smith FJ, Holman CD, Moorin RE, Tsokos N. Lifetime risk of undergoing surgery for pelvic organ prolapse. Obstet Gynecol. 2010;116(5):1096-100. doi:10.1097/AOG.0b013e3181f73729.

6. Vollebregt A, Fischer K, Gietelink D, van der Vaart CH. Primary surgical repair of anterior vaginal prolapse: a randomised trial comparing anatomical and functional outcome between anterior colporrhaphy and trocar-guided transobturator anterior mesh. BJOG. 2011;118(12):1518-27. doi:10.1111/j.1471-0528.2011.03082.x.

7. Diez-Itza I, Aizpitarte I, Becerro A. Risk factors for the recurrence of pelvic organ prolapse after vaginal surgery: a review at 5 years after surgery. Int Urogynecol J Pelvic Floor Dysfunct. 2007;18(11): 1317-24. doi:10.1007/s00192-007-0321-0.

8. Hendrix SL, Clark A, Nygaard I, Aragaki A, Barnabei V, McTiernan A. Pelvic organ prolapse in the Women's Health Initiative: gravity and gravidity. Am J Obstet Gynecol. 2002;186(6):1160-6.

9. Miedel A, Tegerstedt G, Morlin B, Hammarstrom M. A 5-year prospective follow-up study of vaginal surgery for pelvic organ prolapse. Int Urogynecol J Pelvic Floor Dysfunct. 2008;19(12): 1593-601. doi:10.1007/s00192-008-0702-z.

10. Whiteside JL, Weber AM, Meyn LA, Walters MD. Risk factors for prolapse recurrence after vaginal repair. Am J Obstet Gynecol. 2004;191(5):1533-8. doi:10.1016/j.ajog.2004.06.109.

11. Salvatore S, Athanasiou S, Digesu GA, Soligo M, Sotiropoulou M, Serati M, et al. Identification of risk factors for genital prolapse recurrence. Neurourol Urodyn. 2009;28(4):301-4. doi:10.1002/nau.20639.

12. Weemhoff M, Vergeldt TF, Notten K, Serroyen J, Kampschoer PH, Roumen FJ. Avulsion of puborectalis muscle and other risk factors for cystocele recurrence: a 2-year follow-up study. Int Urogynecol J. 2012;23(1):65-71. doi:10.1007/s00192-011-1524-y.

13. Vergeldt TF, van Kuijk SM, Notten KJ, Kluivers KB, Weemhoff M. Anatomical cystocele recurrence: development and internal validation of a prediction model. Obstet Gynecol. 2016;127(2):341-7. doi:10.1097/aog.0000000000001272.

14. Vergeldt TF, Weemhoff M, IntHout J, Kluivers KB. Risk factors for pelvic organ prolapse and its recurrence: a systematic review. Int Urogynecol J. 2015;26(11):1559-73. doi:10.1007/s00192-015-2695-8.

15. Weemhoff M, Wassen MM, Korsten L, Serroyen J, Kampschoer PH, Roumen FJ. Postoperative catheterization after anterior colporrhaphy: 2 versus 5 days. A multicentre randomized controlled trial. Int Urogynecol J. 2011;22(4): 477-83. doi:10.1007/s00192-010-1304-0.

16. Notten KJ, Weemhoff M, Kluivers KB, Schweitzer KJ, Mulder F, Stoker J, et al. Protocol for translabial 3D-ultrasonography for diagnosing levator defects (TRUDIL): a multicentre cohort study for estimating the diagnostic accuracy of translabial 3D- 
ultrasonography of the pelvic floor as compared with MR imaging. BMC Womens Health. 2011;11:23. doi:10.1186/1472-6874-11-23.

17. Notten KJ, Kluivers KB, Futterer JJ, Schweitzer KJ, Stoker J, Mulder FE, et al. Translabial three-dimensional ultrasonography compared with magnetic resonance imaging in detecting levator ani defects. Obstet Gynecol. 2014;124(6):1190-7. doi:10.1097/aog.0000000000000560.

18. Shumaker SA, Wyman JF, Uebersax JS, McClish D, Fantl JA. Health-related quality of life measures for women with urinary incontinence: the Incontinence Impact Questionnaire and the Urogenital Distress Inventory. Continence Program in Women (CPW) Research Group. Qual Life Res. 1994;3(5): 291-306.

19. Bump RC, Mattiasson A, Bo K, Brubaker LP, DeLancey JO, Klarskov $\mathrm{P}$, et al. The standardization of terminology of female pelvic organ prolapse and pelvic floor dysfunction. Am J Obstet Gynecol. 1996;175(1):10-7.

20. Baden WF, Walker TA. Genesis of the vaginal profile: a correlated classification of vaginal relaxation. Clin Obstet Gynecol. 1972;15(4):1048-54.

21. Swift S, Woodman P, O’Boyle A, Kahn M, Valley M, Bland D, et al. Pelvic Organ Support Study (POSST): the distribution, clinical definition, and epidemiologic condition of pelvic organ support defects. Am J Obstet Gynecol. 2005;192(3):795-806. doi:10.1016 jj.ajog.2004.10.602.

22. Whitcomb EL, Rortveit G, Brown JS, Creasman JM, Thom DH, Van Den Eeden SK, et al. Racial differences in pelvic organ prolapse. Obstet Gynecol. 2009;114(6):1271-7. doi:10.1097/AOG.0b013e3181bf9cc8.
23. Parazzini F, De Aloysio D, Di Donato P, Giulini NA, Modena B, Cicchetti $G$, et al. Risk factors for genital prolapse in nonhysterectomized women around menopause: Results from a large cross-sectional study in menopausal clinics in Italy. Eur J Obstet Gynecol Reprod Biol. 2000;93:135-40.

24. Kudish BI, Iglesia CB, Gutman RE, Sokol AI, Rodgers AK, Gass $\mathrm{M}$, et al. Risk factors for prolapse development in white, black, and Hispanic women. Female Pelvic Med Reconstr Surg. 2011;17(2): 80-90. doi:10.1097/SPV.0b013e31820e5d06.

25. Handa VL, Garrett E, Hendrix S, Gold E, Robbins J. Progression and remission of pelvic organ prolapse: a longitudinal study of menopausal women. Am J Obstet Gynecol. 2004;190(1):27-32. doi:10.1016/j.ajog.2003.07.017.

26. Gilchrist AS, Campbell W, Steele H, Brazell H, Foote J, Swift S. Outcomes of observation as therapy for pelvic organ prolapse: a study in the natural history of pelvic organ prolapse. Neurourol Urodyn. 2013;32(4):383-6. doi:10.1002/nau.22298.

27. Dietz HP. Prolapse worsens with age, doesn't it? Aust N Z J Obstet Gynaecol. 2008;48(6):587-91. doi:10.1111/j.1479-828X.2008.00904.x.

28. Mant J, Painter R, Vessey M. Epidemiology of genital prolapse: observations from the Oxford Family Planning Association Study. Br J Obstet Gynaecol. 1997;104(5):579-85.

29. Tegerstedt G, Hammarstrom M. Operation for pelvic organ prolapse: a follow-up study. Acta Obstet Gynecol Scand. 2004;83(8): 758-63. doi:10.1111/j.0001-6349.2004.00468.x.

30. Handa VL, Jones M. Do pessaries prevent the progression of pelvic organ prolapse? Int Urogynecol J Pelvic Floor Dysfunct. 2002;13(6):349-51. doi:10.1007/s001920200078. discussion 352. 